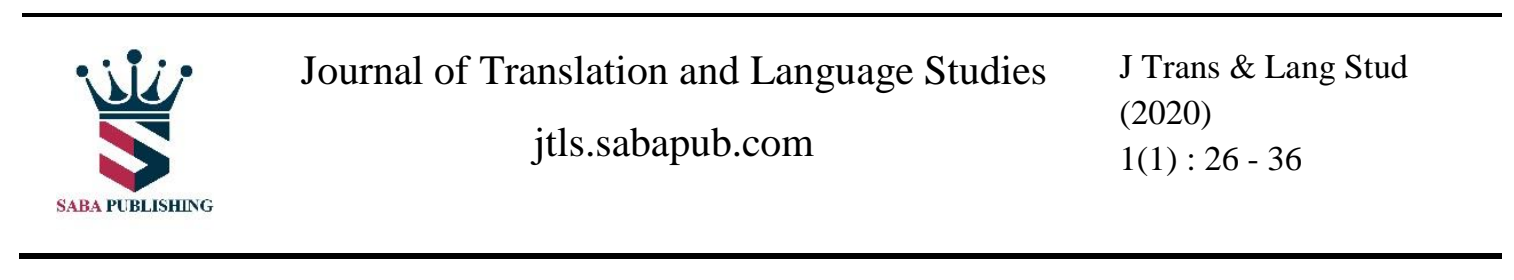

\title{
Pragmatic Hedges in Editorials: A Focus on Vanguard, Guardian and Sun Newspaper Editorials in 2017
}

\author{
Ikosomi Constance $\mathrm{Omo}^{1} \odot$, Idegbekwe Destiny ${ }^{2, *}$ \\ ${ }^{1}$ School of Pre-Degree/ Basic Studies, Niger Delta University, Wilberforce Island,Bayelsa State, \\ Nigeria \\ ${ }^{2}$ Department of English, University of Africa, Bayelsa State, Nigeria.
}

Received: $20.09 .2020 \quad$ • Accepted/Published Online: $15.11 .2020 \quad$ • Final Version: 15.11.2020

\begin{abstract}
Many studies have been carried out on the operations of hedges in different language discourse especially in scientific reports and academic writing. Amongst these studies, none has focused on the operations, functions and layout of hedges in Nigerian newspapers. It is on this basis therefore that the current study pays attention to nature and pragmatic functions which hedges are deployed in Nigerian newspaper editorials. It is the academic gap which the present study unravels. The study used the categorisation of hedges provided by Salager Meyer (1994) as the theoretical framework. The study sampled six editorials each from the 2017 editorials of the Vanguard, Guardian and Sun newspapers, making a total of 18 editorials for analysis. At the end, the study presents amongst other findings that the shield hedges were the more frequently used hedges in the newspaper editorials as all the newspapers used it. On the other hand, the study found out that no newspaper editorial used the compound hedge as there was none found in the sampled data.
\end{abstract}

Keywords: Hedges; pragmatics, shields, editorials, newspapers.

\section{Introduction}

Newspaper editorials remain an avenue for newspaper houses to project their opinions, ideologies and serve as a voice on burning social, political or economic issues in society. Editorials could also be used to set agenda, shift focus and determine the way the polity should go by shaping peoples' opinions through a well thought out communication. To do this, the news houses use language as a major tool for communicating these ideas to their teeming readers. However, in the communication processes, the newspaper reserves the right to choose what to say and how to say it to the readers just like every language user. They can also in an implicit manner relate to the readers how certain or doubtful they are with the information they are giving out to the audience. This is the point at which hedging comes in editorials. Hedging refers to a linguistic process by which a speaker or a writer shields from fully committing to vouching for the authenticity of the facts they are giving out. According to Hyland (1996, p.1), 'hedging is the expression of tentativeness and possibility.'

\footnotetext{
* Corresponding Author: idegbedest@gmail.com
} 
The earliest view of hedges was that it was an unscientific imprecision and 'linguistic cues of bias' (Fand, 1989), i.e., understatements used to convey vagueness and tentativeness, and to make sentences more acceptable to the hearer/reader, thus increasing their chance of ratification and reducing the risk of negation. This necessity for ratification is caused by the inherent refutability of sentences. Indeed, Lakoff (1972) pointed out that natural language sentences are very often neither true nor false nor nonsensical, but rather true to a certain extent and false to a certain extent, true in certain respects and false in others. He then referred to hedges as "words or phrases whose job is to make things more or less fuzzy." Along the same lines, Myers (1988) argued that claiming precision is not appropriate in all situations and that scientists do not always want to be precise: "Sometimes we want to be vague," assert Kong et al. (1986). This concept of fuzziness and (necessary) imprecision was developed further by other researchers, such as Brown and Levinson (1978) who considered hedges as strategies for minimizing the threat to face that lurks behind every act of communication, Lachowicz (1981), Prince et al. (1982), Rounds (1982), Powell (1985), Pindi et al. (1986), Skelton (1988), Dubois (1987), Vasquez (1987). Myers (1988), based his discussion on Brown and Levinson's work (1978), arguing that hedges can be better understood as positive or negative "politeness strategies", i.e., as rational strategies used for dealing with the social interactions involved in publishing an article (e.g., solidarity with readers, unspeakability of direct criticisms, deference towards the scientific community).

The promoters of the other viewpoint of hedges consider that the association of hedging with vagueness or fuzziness can obscure some important function of hedging (cf. SalagerMeyer, 1993). Instead of interpreting the use of hedgings solely in this way, one could alternatively consider them as ways of being more precise in reporting results. Hedging may present the true state of the writers' understanding, namely, the strongest claim a careful researcher can make. Referring to academic writing, Rounds (1981) noted that hedges are not used simply to cover oneself and to make things fuzzy, but that they can also be used to negotiate the right representation of the state of the knowledge under discussion, i.e., to achieve greater preciseness in scientific claims.

Hedging is important to newspaper editorials because there are points in which there would be needs to present facts or strands of information which have not to be proven beyond a reasonable doubt to the public. The newspaper house might also wish to absolve itself of negative legal implication and unnecessary hasty generalisations. Hedging has received a great deal of attention in conversation analysis where devices such as I think, sort of, maybe and possibly are frequently used to create conviviality, facilitate discussion, show politeness and oil the phatic wheels (eg Holmes, 1984 \& 1995; Coates, 1987). Hedges have also been associated with conveying purposive vagueness (eg Powell, 1985; Dubois, 1987; Channell, 1994), treated as a form of meta discourse (eg Vande Kopple, 1985; Crismore, Markkaned \& Steffensen, 1993) and as a means of achieving distance between a speaker and what is said (eg Prince et al, 1982; Skelton, 1988). The nature and pragmatic functions which hedges are deployed in Nigerian newspaper editorials have not been investigated and it is an academic gap which the present study intends to unravel. 


\section{Review of Related Literature}

Ewata (2017) focused on linguistic hedging as a tool for conflict management in academic discourse. The study focused on the Nigerian academic discourse and argued that scholars, universally, deliberately employ linguistic hedging as a conflict management stratagem to manage conflictual situations in the course of their work. Using corpus linguistics methodologies, the work examines inaugural lectures of the Nigerian academic discourse to establish the usage of linguistic hedging devices in analysing the data. Working with 40 purposively sampled inaugural lectures from 10 faculties/schools, from the Nigerian university, the study categorises the hedging devices into typologies to determine their frequency of usage in analysing the data. Four objectives and four research questions were drawn for the work. The study provides an awareness into the working and understanding of academic discourse generally and helps in the development of technical input in designing teaching materials for academic writing.

In another study, Hyland (1996) focused on the use of hedges in scientific writings. The study argued that hedges in scientific texts are the result of informational, rhetorical and personal choices which cannot be fully understood in isolation from social and institutional contexts. Linguistic analyses alone cannot provide a rationale for such choices. According to Hyland (1996), research articles clearly reveal the relationship between a discourse community, standards of knowledge and textual representations and it is these in combination which motivate the use of hedges. Hedges are abundant in science and play a critical role in academic writing more generally. They constitute an essential element of argumentation in presenting new claims for ratification, and are among the primary features which shape the research article as the principal vehicle for new knowledge. An understanding of their use therefore has important implications for a number of areas, and can contribute to the growing literature on the rhetoric of science, revealing important insights into how science establishes its claims to knowledge and how scientists carry out their work.

Duman (2016) focused on a study that examined the hedging in academic writings of English as Foreign Language students using a Chem Corpus method of analysis. Duman (2016) study used 52 academic papers by magister students majoring English at Chemnitz University of Technology as the primary data. The data including 103329 words were analysed by using the AntConc software focusing on the copulas other than 'be'. The study revealed that the most frequently used copula was 'become' in terms of base, present and past form. Additionally, the use of hedging was investigated considering gender differences and it was concluded that similar hedges were frequently used by both male and female students. Lastly, there appeared to be slight differences in terms of the distribution of the selected hedges for both groups. In all, Duman (2016) revealed that the results obtained had in common with previous studies regarding the most frequently used copulas. Duman (2016) then concluded that the copula 'become' and 'seem' were the most frequently used hedges in the Mag written section of the ChemCorpus similar to the findings of the studies by Abdollahzadeh (2011) and Serholt (2012). As part of the recommendations, Duman (2016) noted that the number of hedges used in the academic papers might be resulted from the limited hedging repertoire of the EFL students. To this end, educators might focus on the types and judicious uses of hedges in academic writing. 
In the editorials of the Vanguard, the Guardian and the Sun newspapers, different pragmatic hedges are used to create shields, deliberate vagueness and subtle reactions and responses in relation to the topic of editorial. The objective is to investigate the nature of the use of pragmatic hedges in the newspaper editorials of the Vanguard, the Guardian and the Sun newspapers. The study has the following as the specific objectives:

- to investigate the pragmatic function of the hedges in the newspaper editorials,

- to unravel the most frequently used hedging technique or category.

\section{Theoretical Framework}

\subsection{Salager- Meyer's Hedges Categorisation}

The theoretical framework that was adopted to guide this study is Salager- Meyer's (1994) hedges categorisation. This theory helps us in grouping hedges into different categories, their basic forms and their functions. Before the emergence of this categorisation, the study of hedges was somewhat a blind throw kind of study as different elements could be highlighted by different researchers as hedging. Salager-Meyer (1994) presented the definition of hedges as a three-dimensional concept:

that of purposive fuzziness and vagueness (threat-minimizing strategy); that which reflects the authors' modesty for their achievements and avoidance of personal involvement; and that related to the impossibility or unwillingness of reaching absolute accuracy and of quantifying all the phenomena under observation (p. 153).

In line with her definition of hedging above, Salager-Meyer (1994) identified five main categories. Salager- Meyer's (1994) classification of hedges are discussed below and the classifications are followed for the analysis.

1. Shields: all modal verbs expressing possibility; semi-auxiliaries like "to appear," "to seem" (also called "plausibility shields" in Prince et al. 1982); probability adverbs like "probably," "likely" and their derivative adjectives; epistemic verbs (that is, verbs which relate to the probability of a proposition or a hypothesis being true) such as "to suggest," "to speculate."

2. Approximators: stereotyped "adaptors" as well as "rounders" (see Prince et al. 1982) of quantity, degree, frequency and time (e.g. "approximately," "roughly," "somewhat," "quite," "often, "occasionally") which express heed and coyness. Approximators are the hedging category which most closely reflect what we could call the "institutionalized" language of science.

3. Expressions such as "I believe, "to our knowledge" " it is our view that ..." which express the authors' personal doubt and direct involvement;

4. Emotionally-charged intensifiers (comment words used to project the authors' reactions) such as "extremely difficult/interesting, "dishearteningly weak," "of particular importance", "particularly encouraging, " "unexpectedly," "surprisingly."

5. Compound hedges which comprised "strings of hedges" (i.e., the juxtaposition of several hedges). Such compound hedges can be double hedges (It may suggest that ...; "it could be suggested that "...), treble hedges (It would seem likely that ..., it seems reasonable to assume), quadruple hedges (It would seem somewhat unlikely that ...). 


\section{Methodology}

The present study is qualitative because it describes the nature of pragmatic hedges as used in newspaper editorials. The study used the 2017 editorials of three of the leading newspapers in Nigeria- the Vanguard, Guardian and the Sun newspapers. Six editorials were randomly sampled from each of the newspapers making a total of 18 editorials for analysis. In the data analysis section, the elements of hedges are highlighted in the extracts from the editorials for easy identification and the purposes of analysis. The analysis follows the categorisation of hedges as stated in the theoretical framework for the study from the study of Salager Meyer (1994).

\section{Data Analysis/ Discussion}

In this section, we presented an extract from the three newspapers to analyse the various categories of hedges.

\subsection{Shields in newspaper editorials}

Shields as a category of hedges help the speaker or writer to express probability in the level of the 'truthfulness' of the fact being communicated. Ordinarily, news houses are expected to communicate to the audience what is true, factual and accurate. This is also true with the editorials. However, there could be instances where the media house needs to exercise caution especially when the accuracy of the information is in doubt, uncertain or probable but still needs to be communicated. We would examine some of these instances with extracts from the three newspapers under focus in the present study. We start by looking at the extract below:

What seems to be a recurring decimal between policemen and drivers of articulated vehicles occurred in Apapa, Lagos, mid last week. A policeman attached to a bank allegedly killed a petrol tanker driver over a parking row that degenerated into violence, and a mob attacked two banks in a reprisal. (Vanguard Newspaper, February, 21 ${ }^{\text {st }}$, 2017)

In the extract above, two words act as shields for the accuracy of the information being communicated. They are seems and allegedly. The first acts as the shield for the first sentence while the other act as the shield for the second sentence. For the first, the editorial is not too sure if the fights or scuffle between the Police and the drivers are constant enough to be called 'a recurring decimal.' However, it would be a safe dive to say it looks like or appear like which seems means in this instance. For the second sentence which uses allegedly as a shield, the editorial hides itself from proclaiming the Police and killers since no competent court has done that as at the time the editorial was written. To avoid the problem of hastily jumping into conclusion and declaring the Police as killers, the editorial shields itself by using the hedge allegedly. This reveals that using hedges can prevent the news house from being sued for libel.

Using the hedge as a shield cuts across the three newspapers under investigation as we can see in the extract below the obvious use of hedges as a shielding technique in the Guardian Newspaper.

Owing to this confounding portrayal of poverty alleviation and also the suspicious intention of the government, certain quarters maintain that the programme may be an 
election gimmickry. (Guardian Newspaper, May, 19 ${ }^{\text {th }}$ 2017)... Whilst this alarm seems appropriate in the light of the alleged importation of dangerous grains and unhealthy food crops into the country, the Ministry of Agriculture needs to do more to facilitate the production of quality food crops and promote the cultivation and consumption of healthy foods. (Guardian newspaper) .... But that dynamism is gone and a business-as-usual disposition seems to have returned to the operations of NAFDAC. (Guardian, April, $11^{\text {th }}$ 2017).

There are four instances where the shield hedges are used in the extract above spanning across three editorials. In the first instances, the modal auxiliary verb, may helps to communicate the idea of probability in the statement that the APC led Federal government is using the conditional cash transfer of Five Thousand Naira to lure voters ahead of elections. In as much as this could be true, it might not be absolutely the case. It might be a noble gesture from the government to reduce poverty in the nation. It could also be that the government was fulfilling its promises made to the electorate during the campaigns. All these other possibilities make it impossible for the editorial to communicate certainty in the aim of government's action in the context of this discourse. In the next instance, two shield elements are used (seems and alleged). We have earlier looked at the use of these two elements in the Vanguard Newspaper. The use in this instance is not too different from the earlier. The hedges here are thrown in for caution and a sense of political correctness especially in the use of the hedge alleged. A group called a press conference condemning the importation of dangerous grains into the nation. The Guardian editorial saw it as something worth talking about because it is appropriate. However, the editorial does not throw in support fully especially if seem is used to describe its 'appropriateness.' This helps the editorial to save its face especially if it is found out later to be inappropriate. This also the case with the use of alleged. It would be wrong to say someone committed a crime of importing dangerous grains into the nation if the courts have not pronounced the individual as such. This becomes 'technical' or an act of political correctness if the speaker has evidence and witnessed such an action. The last instance of the shield hedge in the extract above is the use of seems to communicate the changes in the operations of NAFDAC since Dr. Dora Akunyili left the organisation. While the editorial notes that standard has nosedived, it does not say it for sure because of the use of seem. The statement with seems creates room for doubt and a rethinking of what is happening.

Lastly under the shield hedges, we would consider the extracts from the Sun News editorial. The extracts read thus:

Against this background, the N270 billion estimate for 52 bridges, over three years may definitely go higher, if the political will remains to sustain the initiative. (Sun News, June, $14^{\text {th }}$ 2017)...The above well laid out seamless tradition seems to have been broken or confounded when at the termination of the tenure of Chief Justice Mahmud Muhammed, the NJC did its traditional duty of nominating the most senior justice of the Supreme Court, who happened to be Justice Onnoghen, but the President, rather than forward the nominee's name to the Senate for confirmation, chose to appoint him as acting Chief Justice. (Sun News, October $6^{\text {th }}$ 2017)... Further delay in the confirmation of Onnoghen is likely to lead to misgivings, which could be unhealthy for the polity (Sun News, March, 23 ${ }^{\text {rd }}$ 2017). 
There are four instances of the use of shield hedges in the extracts above in three editorials of the Sun Newspaper. The first two (the use of may and seems) have been well established in our previous analysis. It is good we note that the use is not radically different from the present as they introduce and operate the subjunctive mood of doubt as to the main speech function. We would however focus more on the last two instances (likely and could). Though both shielding elements introduce to the communication elements of doubt and uncertainty, they have not been used in the earlier extracts. In the use of likely and could, the editorial is making a prediction of the political result of not appointing Justice Onnoghen as the Chief Justice of the Federation. However, the editorial leaves room for other possibilities and results as the use of other elements that communicate certainty such as must, shall and the others would present the editorial as boastful and vain. There is nothing scientific about the prediction. So, it could go wrong and if it goes wrong after such a boastful prediction, it would be a thing of shame and may cause embarrassments to the media house. Hence, the shield hedges hide and prevent all the other eventualities.

\subsection{Approximators in newspaper editorials}

Approximators is the second categorisation of hedges which Salager-Meyer (1996) identified. We are going to examine how they operate in the three newspaper editorials we are examining.

The President, Vice President and the Minister of Education were university lecturers, but that does not approximate passion about education. (Vanguard, December 5th, 2017)

Attempts to enforce the law often create frictions between them and security agents. (Vanguard, July 26th, 2017).

According to our working definition of hedges even though not all approximators serve to make things vague, some are indeed used when exact figures are irrelevant or unavailable or when the state of knowledge does not allow the speaker to be more precise. In the extract above, the word approximate and often are used as approximators hedges. Though the working framework does not specifically identify the word approximator as a hedge but in the extract above, the word functions as a hedge. It helps to provide a sense of estimation of the commitment of the President and Vice toward education in a negative sense. This means that it would have been logical to conclude that the two leaders being lecturers would take education seriously. However, such an approximation is in the negative with the use of the not negator as a qualifier. In the second part of the extract, the approximator often helps to communicate the hedge of not too specific frequency of occurrence. In the real sense, presenting the accurate number of times the friction between the security agents and the group took place does not really add so much to the entire communication of the idea. The question would be if it is regular which often suggests or not too regular which seldom suggests. However, one cannot make a clear guess what number in a time frame would amount to often. This is the hedge or coy element in the expression.

We would also examine other extracts below:

That the relevant authorities in Nigeria have begun the processes of dealing decisively with factors that have always made doing business in Nigeria difficult is quite inspiring. (Guardian, 19th January, 2017).... The road alignment is surveyed in detail but ground experience often demands on-site adjustment. (Guardian, February 8th, 2017)... These are 
aspects of the production chain often handled by untrained hands or mischievous persons who want to cut corners. (Guardian, March 13th, 2017).

For the Guardian Newspaper editorial under investigation, there are instances of the use of approximators hedges in the use of quite which expresses coyness or a lack of exactness in the term which it qualifies. Quite as an adverb introduces a sense of 'limiter' to adjective inspiring. However, there roundness attached to its use. As this might mean very inspiring, really inspiring and other forms. In the second use of approximators in the above extract, the hedge often is used to communicate the frequency of occurrence which also has a sense of roundness that could mean always, every time, every now and then etc.

The same trend can also be seen in the extract below:

But, it is quite clear that the Constitution says that it is the duty of the NJC to select the CJN, and that of the president to forward same to the Senate for confirmation. (Sun, March 18th, 2017) ... The demise of a president often comes with great national sadness, but the institutions of government are meant to cushion the state against social convulsion and political turmoil. (Sun, May 20th, 2017)

In the above just like we have seen in the earlier extract, quite is used to 'round up' all the other possibilities in the positive form that can qualify the adjective clear and it helps the editorial to put all the items in one word. For often, the idea of the frequency of occurrence is the same with the extract above. The exact number of times this death and sadness would come to the nation in case a president dies is not known and cannot be ascertained. If the exact number is known however, it is not relevant to the present communication.

\subsection{Expression of Belief in newspaper editorials}

From the investigation of the three newspaper editorial in the year 2017, on the Sun Newspaper used the belief expression on two occasions in the same editorial. The other two newspapers did not use it as a form of a hedge. We would quickly examine the nature of its use in the extracts below:

Going forward, we believe the president should be allowed to have his medical treatment in peace, while Nigerians are duly informed about the progress he is making. (Sun, May $\left.20^{\text {th }}, 2017\right) \ldots$ While some segments of the Nigerian population believe that the president might be dead or incapacitated and have called for his resignation, with some seizing the occasion to embark on public protests against the hardship occasioned by the recession in the country, yet others hold the view that he is alive, well and having a well-deserved rest as afforded him by the Constitution. (Sun, May 20 $0^{\text {th }}$,2017)

It is important we note that the expression of belief is a reaffirmation of the authors thinking and opinion on the subject matter. Though editorials are used to present the opinion of a media house on different issues, they can make it more obvious or explicit by using the expression of belief phrase. For example, in the extract above, the first use is a reaffirmation of the need to allow the President to have his medical break in peace while his aids give an update to the nation regularly. That is the reason for the editorial in the first instance but made more obvious with the use. In the second part of the extract, the use of belief is not for the immediate speaker in terms of the editorial but the world view or the 
opinion of the Nigerian population. This might be an approximation of segments of the Nigerian society but their personal opinion is reported.

\subsection{Emotionally charged words in newspaper editorials}

It is sad that the two banks had to bear the rage of the mobs. (Vanguard, August 25 $5^{\text {th }}$, 2017)... The trend of vote-buying which has become a major feature of recent elections sadly repeated itself in Anambra." Inducements are as old as elections in Nigeria. Sadly, rather than outgrowing it, the Anambra poll signposted the fact that it appears to be getting worse. This does not augur well for our democracy. (Vanguard, November $30^{\text {th }}$, 2017).

Emotionally charged words go a long way in revealing the reaction of the speaker to the object. In this context, it is the reaction of the editorial to the subject of discourse. In the case of the extract above, the words sad and sadly express the emotional reaction of the editorial towards the subject of discourse. It is a kind of hedging because it is not an obvious reaction but implied. The emotional attachment to such an issue vague or implied in the editorial. The fact remains that the communication can be relayed without the emotional words being used. For example, in the first use, the editorial could inform the reader thus: 'the two banks had to bear the rage of the mobs' and in the second instance: 'rather than outgrowing it, the Anambra poll signposted the fact that it appears to be getting worse.' The use of both above would not carry the reaction of the editorial to such actions in the discourse and the editorial would not want to go all out to state that this is our reaction. So, it is subtly dropped or hidden in the emotional words. We would also examine how it is used in other editorials in the extract below:

The signals relayed by this proposal are not encouraging. They portray this poverty alleviation strategy as a classic case of gimmickry and caricature of empowerment. (Guardian, January, 19 ${ }^{\text {th }}$,2017)... Once again, this newspaper restates its position that while the people of Nigeria still await the implementation of the report of the 2014 National Conference, which the Buhari administration claims, sadly, that it has consigned to the archives, Nigerians must begin to look in the direction of a just fiscal policy; one that grants the control of resources to federating units on whose land the resources are located.

In the extract above, encouraging used with the negator is emotionally charged and communicates the reaction of the editorial to the poverty alleviation programme of the Federal government. It would be too critical for them to say expressly that the poverty alleviation programme is bad. Not encouraging could mean they are trying but not enough or not enough at all. The two possible meanings put the news house in a kind of safe place. This also applies to the use of sadly in the second part of the extract. It conveys the response of the editorial to the rejection of the conference report by President Buhari and the fact that he has not even read it. The editorial cannot compel him to read it or implement it but they can change his mind though subtle responses and reactions to the issue.

Lastly, we would look at emotionally charged words from the Sun Newspaper which are presented in the extract below:

This is why we must not fail to appreciate the activities of all pressure groups, both at home and abroad, especially the Bring Back Our Girls (BBOG) campaigners who have continued to prick at the conscience of a seemingly forgetful world, on the need to rescue all 
of the Chibok girls and bring the matter of their sad abduction to a closure. (Sun, May $20^{\text {th }}$, 2017)

In the extract above, the emotionally charged word is sad which communicates the response of the Sun editorial to the neglect of the kidnapped schoolgirls of Chibok. The issue of the kidnapped girls is not the main focus of the editorial for the day. It is brought in to explain the fact that girls' rights have been neglected for far too long especially with the rape of young schoolgirls in Lagos, Nigeria. The expression of the emotion of sadness on the Chibok girls' kidnap is a reaction though subtle. It is the subtleties that make emotionally charged words in editorials function as hedges.

\section{Findings}

From the analysis above, the study presents the following as the findings:

1. That the shield hedges are the most frequently used hedges in the newspaper editorials as all the newspapers used it. On the other hand, the study found out that no newspaper editorial used the compound hedge as there was none found in the sampled data.

2. The study also found out that the use of hedges can help the news house shield themselves from being sued for libel as they can hide under the vagueness which hedges provide.

3. Lastly, the study found out that the use of emotionally charged words in editorials creates a kind of reaction or response that is usually subtle. It is the subtle nature that makes it hedgy in use.

\section{Conclusion}

This study investigated the nature of hedges in Nigerian newspaper editorials with a focus on the Vanguard, the Guardian and the Sun newspapers' editorials in 2017. The study used the categorisation of hedges provided by Salager Meyer (1994) as the framework. The study sampled six editorials from each of the newspapers making a total of 18 editorials for analysis. At the end, the study present amongst other findings that the shield hedges are the more frequently used hedges in the newspaper editorials as all the newspapers used it. On the other hand, the study found out that no newspaper editorial used the compound hedge as there was none found in the sampled data. The study also found out that the use of hedges can help the news house shield them from being sued for libel as they can hide under the vagueness which hedges provide.

\section{References}

[1] Abdollahzadeh, E. (2011). Hedging in postgraduate student theses: a cros-cultural corpus study. International Conference on Languages, Literature and Linguistics, 26, 581586.

[2] Brown, P. \& Levinson, S. C. (1978). Politeness: Some universals in language usage (Vol. 4). Cambridge: Cambridge University Press.

[3] Channell, J. (1994). Vague language. Oxford: Oxford University Press.

[4] Coates, J. (1987). Epistemic modality and spoken discourse. Transactions of the Composition and Communication, 36, 82-93.

[5] Crismore, A., Markkaned, R. \& Steffensen, M. (1993). Metadiscourse in persuasive writing: A study of texts written by American and Finnish university 
[6] Dubois, B. (1987). Something of the order of around 40 to 44. Imprecise numerical expressions in biomedical slide talks. Language and Society, 16: 525-41.

[7] Duman, Z. (2016). Hedging in academic writings of EFL students: ChemCorpus. Journal of Narrative and Language Studies, 4(6), 44-52.

[8] Ewata, T. (2017). Linguistic hedging: Conflict management tool in academic discourse. Modern Research Studies: 12 (3) 2349-2147.

[9] Fand, R. (1989). Detecting bias in newspapers: implications for teaching ESL. Reading in a Foreign Language, 6(1): 315-321.

[10] Holmes, J. (1984). Modifying illocutionary force. Journal of Pragmatics, 8, 345-365.

[11] Holmes, J. (1990). Hedges and boosters in women's and men's speech. Language and communication, 10(3), 185-205.

[12] Holmes, J. (1995). Women, men and politeness. London: Longman.

[13] Hyland, K. (1996). Talking to the academy: Forms of hedging in science research articles. Written Communication, 13(2), 251-281.

[14] Kong, A., D. Barnett, F. Mosteller and C. Youtz. (1986). How medical professionals evaluate expressions for probabilities. New England Journal of Medicine, 315. 740-4.

[15] Lachowicz, D. (1981). "On the use of the passive voice for objectivity, author's responsability and hedging in EST." Science of Science. 2(2). 105-115.

[16] Lakoff, G. (1972). Hedges: A study in meaning criteria and the logic of fuzzy concepts. The 8th Regional Meeting of the Chicago Linguistics Society, 183-228.

[17] Myers, G. (1988). The pragmatics of politeness in scientific articles. Applied Linguistics, 10, 135. Philological society, 85, 100-131.

[18] Pindi, M. \& Bloor, T. (1986). "Playing safe with predictions: hedging, attribution and conditions in economic forecasting." Written Language. BAAL. 2. CILT.

[19] Powell, M. (1985). Purposive vagueness: an evaluation dimension of vague quantifying expressions." Journal of Linguistics. 21: 31-50.

[20] Prince, E.F., R.J. Frader and C. Bosk (1982). "On hedging in physician-physician discourse." In J. di Prieto (Ed.) Linguistics and the Professions. Ablex Publishing Corporation. : 83-97. Rounds, P. (1981). "On hedging in social science written texts." University of Michigan (Mimeo)

[21] Rounds, P. (1982). "Hedging in written academic discourse: precision and flexibility." (Mimeo). University of Michigan.

[22] Salager-Meyer, F. (1993). "Imprecision and vagueness (hedging) in today's medical discourse: courtesy, coyness or necessity?" The ESPecialist. 14(1), 1-15.

[23] Salager-Meyer, F. (1994). Hedges and textual communicative function in medical English written discourse. English for Specific Purposes, 13(2), 149-171.

[24] Serholt, S. (2012). Hedges and boosters in academic writing: A study of gender differences in essays written by Swedish advanced learners of English. Retrieved from https://gupea.ub.gu.se/handle/2077/29526.

[25] Skelton, J. (1988). The care and maintenance of hedges. ELT journal, 42(1), 37-43.

[26] students.Written Communication, 10 (1), 39-71.

[27] Vande Kopple, W. (1985). Some exploratory discourse on metadiscourse. College

[28] Vasquez, F. (1987) A comparative Study of the Rhetorical Structure of the Discussion Sections in English and Spanish Medical Articles. Msc. TESP. Aston University. 